\title{
Postoperative Occlusion of the Small Bowel with Flanges and/or Adhesions in General Surgery of Kati BSS CHU
}

\author{
Abdoulaye Diarra ${ }^{1}$, Koniba Keita ${ }^{1}$, Amadou Traoré1, Assitan Koné1, Issa Traore ${ }^{1}$, \\ Idrissa Tounkara ${ }^{1}$, Abdoulaye Kante ${ }^{1}$, Fadima K Tall2, Daouda Diallo², \\ Moustaph Issa Magané2, Madiassa Konate1, Aboubacar Koné1, Deborah Sanra Sanogo33, \\ Ismaël Konare ${ }^{1}$, Alhassane Traoré ${ }^{1}$ \\ ${ }^{1}$ General Surgery Department, Kati, Mali \\ ${ }^{2}$ Anesthesia Service and Resuscitation Department, Kati, Mali \\ ${ }^{3}$ Gastroenterology Department, Kati, Mali \\ Email: *abdoulayeg2004@yahoo.fr
}

How to cite this paper: Diarra, A., Keita, K., Traoré, A., Koné, A., Traore, I., Tounkara, I., Kante, A., Tall, F.K., Diallo, D., Magané, M.I., Konate, M., Koné, A., Sanogo, D.S., Konare, I. and Traoré, A. (2018) Postoperative Occlusion of the Small Bowel with Flanges and/or Adhesions in General Surgery of Kati BSS CHU. Surgical Science, 9, 293-299.

https://doi.org/10.4236/ss.2018.99035

Received: September 3, 2018

Accepted: September 14, 2018

Published: September 17, 2018

Copyright ( $\odot 2018$ by authors and Scientific Research Publishing Inc. This work is licensed under the Creative Commons Attribution International License (CC BY 4.0).

http://creativecommons.org/licenses/by/4.0/

\begin{abstract}
Objectives were to determine the frequency, describe the epidemiological and clinical aspects, therapeutic and analyze the postoperative course. Methodology: This was a retrospective study that covered 08 years (January 2009-December 2017). Inclusion criteria: all patients operated for obstruction of the small bowel by hail and/or flanging. Exclusion criteria: other types of occlusion and non-operated patients. Result: We recorded a total of 162 cases of hail obstruction by adhesions and/or flanges at $2.87 \%$. The average age was 32.04 , the sex ratio was 1.2. The average consultation time was 4 days. Abdominal pain associated with stopping of material and gas was present in all our patients. X-ray of the abdomen without preparation carried out in all the patients made it possible to objectify in 150 patients (92.6\%) of the hydro-hail levels. Inoperative occlusion of hail on flange was present in 80 patients (49.4\%). Occlusion of the small bowel on flange and adhesion was present in 69 patients. Adhesion obstruction of hail accounted for 6.8\% (11 cases). The most commonly used surgical technique was flange resection in 91 patients (56.2\%). The follow-up was simple in 151 patients (93.2\%). Mortality was $1.2 \%$ of cases, i.e. 2 deaths. The average duration of hospitalization was 6 days. Conclusion: Occlusion of the small bowel by flanging and/or adherence is a surgical emergency whose prognosis depends on early management.
\end{abstract}

\section{Keywords}

Postoperative Occlusion, Hail, Bridle/Adherence, Mali 


\section{Introduction}

Post-operative occlusions by flange and/or adhesions constitute a surgical emergency. They represent a common and expensive complication of abdominal surgery. At C.H.U. Gabriel Touré they represent $2.93 \%$ of surgical emergencies and $61.75 \%$ of acute intestinal occlusions.

Bridles and adhesions are structures found in $95 \%$ of patients with previous abdominal procedures [1] [2]. They are directly related to surgical trauma even if it is minimal. JOHANET [3] shows that after laparotomy, one patient in a hundred will present an occlusion by flange and adhesion in the year following the intervention and that in the very long term 3 patients out of a hundred will have to suffer from this pathology.

Miller G [4] shows that in 1992 there were 12,000 to 14,400 cases of hail obstruction in the United Kingdom by flanges and/or adhesions per year, which corresponds to an incidence of 200 cases/100,000 inhabitants.

Occlusions of the small bowel with flanges and adhesions represent a common and expensive complication of abdominal surgery.

In Europe they are the leading cause of small bowel obstruction (70\%) [1]-[6] with a non-negligible mortality of $4 \%$ to $17 \%$ depending on the series [5] [6]. In Africa they have been the object of several studies. In Niger, Harouna et al. [7] estimated that they represent $39.3 \%$ of bowel obstruction and affect a population that is often very young.

Increasingly his laparoscopic treatment has been the subject of several studies.

The objectives were to determine the hospital frequency of postoperative small bowel obstruction in the general surgery department, to describe the therapeutic epidemiological aspects of the treatment and to analyze the operative follow-up.

\section{Materials and Methods}

We conducted a retrospective study that covered 8 years (January 2009-December 2017). It was performed in the General Surgery Department at Kati HCSS.

Inclusion criteria: All patients operated for small bowel obstruction by adhesions and/or flanges, the diagnosis of which has been confirmed.

Exclusion criteria: We excluded other types of occlusion and non-operated patients.

The variables studied were: age, sex, clinical signs, radiological signs, operative techniques. The source of the data was the patient's records, the operating record register, the hospitalization record. EPI-INFO software 7 was used to analyze the data. The validity test of the results is the Chi-square with probability threshold $\mathrm{P}<0.005$.

\section{Result}

We recorded a total of 162 cases of hail obstruction by adhesions and/or flanges, i.e. $2.87 \%$ of surgical emergencies and $60.95 \%$ of acute intestinal occlusions. The 
average age was 32.04 years + or - 11.50 with extremes of 15 and 75 years (Figure 1), the sex ratio was 1.2 (Figure 2). The average consultation time was 4 days (with extremes of 1 and 15 days). All our patients had a surgical history. Abdominal pain associated with stopping of material and gas was present in all our patients. Vomiting was found in 155 patients (95.6\%), 9 patients (5.5\%) showed signs of dehydration. The physical signs found on examination are grouped in Table 1. X-ray of the abdomen without preparation carried out in all the patients made it possible to objectify in 150 patients $(92.6 \%)$ of the hydro-hail levels. All the patients were operated on. In operative room occlusion of small bowel was present in 80 patients $(49.4 \%)$ of whom 11 had intestinal necrosis (6.8\%). Occlusion of small bowel and adhesion was present in 69 patients without necrosis. Adhesion obstruction of hail accounted for $6.8 \%$ (11 cases). The operative techniques were: flange resection in 91 patients (56.2\%), flange resection and adhesiolysis in 40 patients (24.7\%), adhesiolysis in 20 patients $(12.3 \%)$, resection of the flange and anastomosis resection in 9 patients $(5.5 \%)$, resection of the flange and ileostomy in 2 patients (1.2\%). The follow-up was simple in 151 patients (93.2\%). Table 2 groups the complications according to the different operating techniques. We recorded 5 cases of parietal suppuration (3.1\%), 1 case of digestive fistula (0.6\%), and 2 cases of postoperative evisceration (1.2\%). Mortality was $1.2 \%$ of cases, i.e. 2 deaths. The average duration of hospitalization was 6 days.

\section{Discussion}

Postoperative occlusion is a surgical entity characterized by the formation of a fibrous membrane especially on the small bowel. We recorded a frequency of $1.6 \%$ comparable statistically to that of Moroccan series [8].

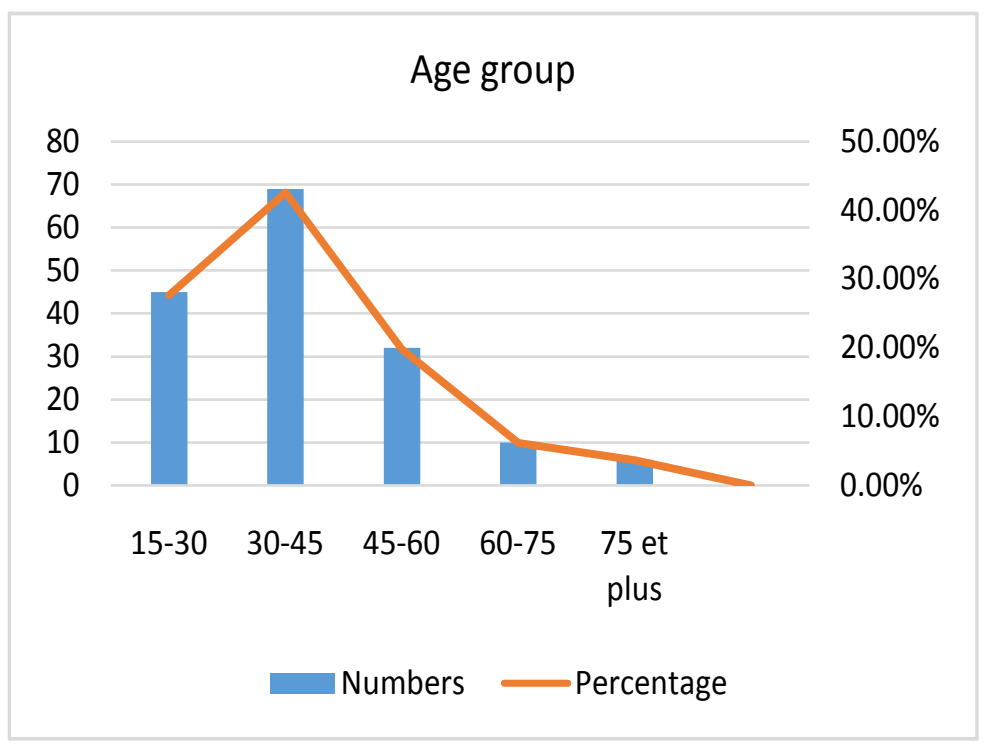

Figure 1. Age group. 


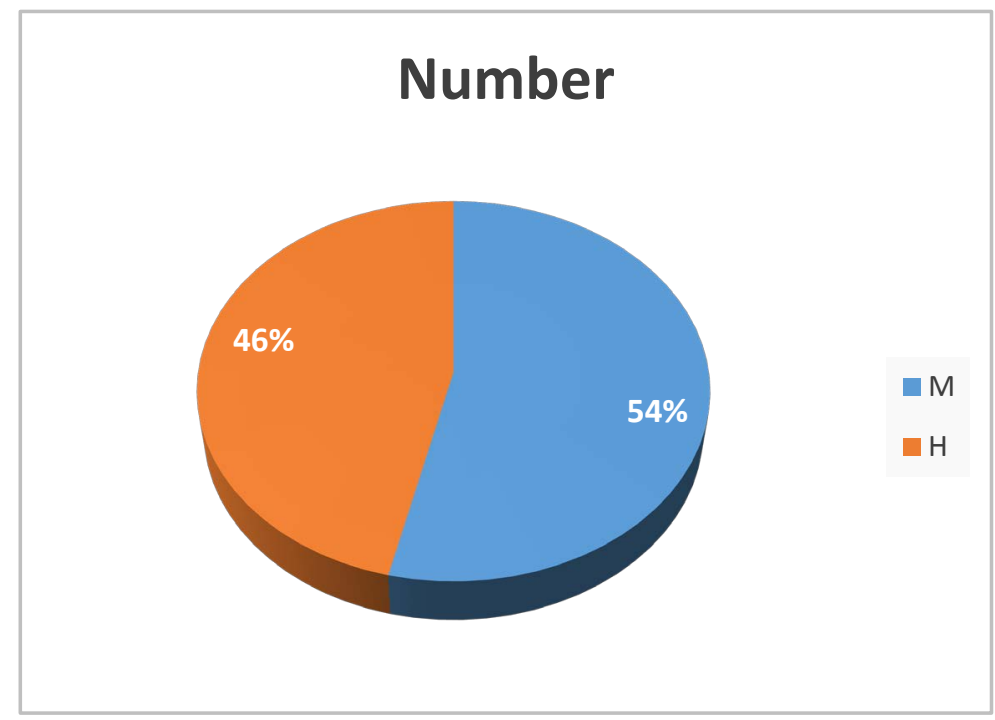

Figure 2. Sex.

Table 1. Physical Signs.

\begin{tabular}{cccc}
\hline & Signs & Numbers & Percentage \\
\hline \multirow{3}{*}{ Inspection } & Abdominal scar & 162 & $100 \%$ \\
& Abdominal distention & 80 & $49.4 \%$ \\
\multirow{3}{*}{ Palpation } & Abdominal defense & 20 & $12.3 \%$ \\
& Abdominal meteorism & 75 & $46.3 \%$ \\
\multirow{3}{*}{ Percussion } & contracture & 12 & $7.4 \%$ \\
& Abdominal tympanism & 75 & $46.3 \%$ \\
& Mateness of flanks & 14 & $8.6 \%$ \\
& Increased hydro-aerial noise & 70 & $43.2 \%$ \\
& Auscultatory silence & 10 & $6.2 \%$ \\
\hline
\end{tabular}

Table 2. Operative gestures and postoperative morbidity.

\begin{tabular}{ccccc}
\hline & \multicolumn{4}{c}{ Post operative } \\
\cline { 2 - 5 } Operative procedures & Suite simples & $\begin{array}{c}\text { Surgical site } \\
\text { infection }\end{array}$ & $\begin{array}{c}\text { Digestive } \\
\text { fistula }\end{array}$ & $\begin{array}{c}\text { Post operative } \\
\text { evisceration }\end{array}$ \\
\hline $\begin{array}{c}\text { Section of the flange } \\
\text { Flange resection and } \\
\text { adhesiolysis }\end{array}$ & 91 & 2 & 0 & 1 \\
$\begin{array}{c}\text { adhesiolysis } \\
\text { Flange resection and } \\
\text { anastomosis resection }\end{array}$ & 40 & 1 & 0 & 0 \\
$\begin{array}{c}\text { Resection of the flange } \\
\text { and ileostomy }\end{array}$ & 20 & 0 & 0 & 0 \\
Total & 152 & 2 & 1 & 1 \\
\hline
\end{tabular}

Significant difference between operative technique performed and postoperative morbidity with $\mathrm{P}<0.05$. 
We recorded a younger population with an average age of 34 years compared with Western series [9] [10] [11] [12] $(\mathrm{P}=0.05)$. This difference could be explained by the younger population in Africa compared to a more aging Western population.

Abdominal pain and vomiting are very common symptoms of small bowel obstruction [13] [14]. We had a proportion ranging from $97.1 \%$ to $100 \%$ of vomiting, stopping of material and gas and abdominal pain.

$\mathrm{X}$-ray of the abdomen without preparation is the first-line examination to be made when there is suspicion of small bowel obstruction [13] [15]. All our patients achieved ASP (100\%) this does not differ from the Harouna study in Niger (91.9\%) [13] $\mathrm{P}=0.55$. The benefits of this radiological examination are the lower cost and easy achievement in regional hospitals in Mali. For centers that are equipped, abdominopelvic computed tomography (CT) with or without injection of contrast medium is becoming increasingly important. It allows at the same time to pose the diagnosis with certainty but especially the diagnosis of gravity. The operative technique performed depends on the state of the loop, the condition of the patient, the risk factors, whatever the cause of the occlusion flanges and/or adhesions [16] [17].

Table 3 summarizes the various operative techniques according to the authors.

In the literature the mortality varies according to the authors $3.4 \%$ and $7.7 \%$ [18].

The mortality in our study (1.2\%) does not differ from that of the Norwegian series.

The delay in consultation, the age of the patient and his general condition could increase this mortality.

Infection of the operative site is the most common early postoperative complication in digestive surgery [7] [19]. The same finding was made in our study (3.1\%)

Digestive fistula is a serious complication of digestive surgery. According to the authors, this fistula varies from $2.3 \%$ to $5.7 \%$ [7] [13] [15] [19] [20].

All the fistulas of our series have dried up during the duration of the hospitalization and only the medical treatment (local, nutritional care) was used.

Table 3. Technique according to authors.

\begin{tabular}{cccccc}
\hline Authors & $\begin{array}{c}\text { Flange } \\
\text { section } \\
\mathbf{n}(\%) \mathbf{P}\end{array}$ & $\begin{array}{c}\text { Clamp and } \\
\text { adhesiolysis } \\
\text { section } \\
\mathbf{n ~ ( \% ) ~ P ~}\end{array}$ & $\begin{array}{c}\text { Adhesiolysis } \\
\mathbf{n}(\%) \mathbf{P}\end{array}$ & $\begin{array}{c}\text { Resection } \\
\text { anastomosis } \\
\mathbf{n}(\%) \mathbf{P}\end{array}$ & $\begin{array}{c}\text { Ileostomy } \\
\mathbf{n}(\%) \mathbf{P}\end{array}$ \\
\hline $\begin{array}{c}\text { Beyrout Tunisie } \\
\text { 2006 [19] }\end{array}$ & $\begin{array}{c}152(59) \\
\mathbf{0 . 2 1 4 8}\end{array}$ & - & $54(21.1)$ & $30(11.6)$ & $7(6.5)$ \\
Kouadio & $25(51)$ & $2(4.1)$ & $5(10.2)$ & $17(34.7)$ & $\mathbf{0 . 3 2 5 8}$ \\
RCI2004 [13] & $\mathbf{0 . 6 2 3 3}$ & 0.0008 & $\mathbf{0 . 8 0 4 6}$ & 0.0001 & - \\
Duron France & $130(45)$ & $24(8)$ & $56(19.6)$ & $31(11)$ & $4(1.4)$ \\
2006 [21] & $\mathbf{0 . 5 4 3 8}$ & 0.0022 & $\mathbf{0 . 0 0 9 0}$ & $\mathbf{0 . 0 2 5 9}$ & $\mathbf{0 . 5 4 8 4}$ \\
Our study Mali & $91(56.2 \%)$ & $40(24.7 \%)$ & $20(12.3 \%)$ & $9(5.6 \%)$ & $2(1.2 \%)$ \\
2017 & & & & & \\
\hline
\end{tabular}




\section{Conclusions}

The occlusion of the hail by bridle and/or adhesion is a surgical emergency that in Africa affects a population often very young, whose prognosis depends on the early management.

Delayed consultation and certain comorbidities (diabetes, high blood pressure) may be life-threatening for patients.

\section{Conflicts of Interest}

The authors declare no conflicts of interest regarding the publication of this paper.

\section{References}

[1] Dargent, J., Caillot, J.L. and Chalbet J Y. (1987) Occlusions post-opératoires tardives du grêle par brides. Etude rétrospective de 47 dossiers, facteur de pronostic. Lyon Chirurgical, 83, 404-406.

[2] Ivarsson, M.L., Holmdahl, L. and Franzen, G. (1997) Cost of Bowel Obstruction Resulting from Adhesions. The European Journal of Surgery, 163, 679-684.

[3] Johanet, H., Traxer, O. and Manceau, C. (1999) Occlusion aiguës du grêle par bride et adhérences. Annales de Chirurgie, 53, 859-886.

[4] Miller, G., Boman, J. and Shier, I. (2000) Natural History of Patients with Adhesive Small Bowel Obstruction. British Journal of Surgery, 87, 1240-1247. https://doi.org/10.1046/j.1365-2168.2000.01530.x

[5] La Gamma, A., Letoquart, J.P. and Kunin, N. (1994) Les occlusions du grêle par brides et adhérences. Analyse sur 157 Cas opérés. Journal de Chirurgie, 131, 279-284.

[6] Montz, F.J., Holschneider, C.H., Solh, S., Schuricht, L.C. and Monk, B.J. (1994) Small Bowel Obstruction Following Radical Hysterectomy: Risk, Incidence and Operative Findings. Gynaecologic Oncology, 53, 114-120.

[7] Harouna, Y., Maazou, I. and Almoustapha, I. (2005) Les occlusions intestinales aiguës par brides: A propos de 87 cas. Médecine d Afrique Noire, 935, 317-319.

[8] Makhouad, R. (2018) Etude rétrospective des occlusions intestinales: Diagnostic et prise en charge (service de chirurgie viscérale; Hit Marrakech). Thèse de Médecine, Université Cadi Ayyad, Marrakech.

[9] Kössi, J., Salminen, P. and Laato, M. (2004) The Epidemiology and Treatment Patterns of Postoperative Adhesion Induced Intestinal Obstruction in Varsinais-Suomi Hospital District. Scandinavian Journal of Surgery, 93, 68-72.

https://doi.org/10.1177/145749690409300115

[10] Catel, L., Lefèvre, F., Laurent, V., Canard, L., Bresier, L., Guillemin, F.D., et al. (2003) Occlusion sur bride. Quels critères scanographiques de gravité rechercher? Journal of Radiology, 84, 27-31.

[11] Hiki, N., Takeshita, Y., Kubota, K., Tsugi, E., Yamaguchi, H., Shimizu, N., et al. (2004) A Seasonal Variation in the Onset of Postoperative Adhesive Small Bowel Obstruction Is Related to Changes in the Climate. Digestive and Liver Disease, 36, 125-129. https://doi.org/10.1016/j.dld.2003.10.008

[12] Naeem, G., Kemp, K.M., Bannon, M.P., et al. (2015) Early Postoperative Small Bowel Obstruction: Open vs Laparoscopic. American Journal of Surgery, 209, 385-390. 
https://doi.org/10.1016/j.amjsurg.2014.07.012

[13] Kouadio, G.K. and Turquin, T.H. (2004) Prise en charge des occlusions post-opératoires du grêle par brides et adhérences au CHU de Treichville à Abidjan. Médecine $d$ Afrique Noire, 51, 629-632.

[14] Tseng, C.J., Sun, D.P., Lee, I.C., Weng, S.F. and Chou, C.L. (2016) Factors Associted with Smoll Bowel Obstruction Following Appendectomy: A Population-Based Study. Medecime, 95, e3541.

[15] Dembélé, B.T., Traoré, A. and Diakité, I. (2011) Occlusion du grêle sur bride et adhérence en chirurgie générale CHU Gabriel Touré. Mali Médical, 26, 12-15.

[16] Stephen, W., et al. (2014) A Comparative Analysis between Laparoscopic and Open Adhesiolysis at a Tertiary Care Center. The American Surgeon, 80, 261-269.

[17] Bjorg, T.F., Fevang, J. and Stangeland, L. (2000) Complications and Death after Surgical Treatment of Small Bowel Obstruction: A 35-Year Institutional Experience. Annals of Surgery, 231, 529-537.

[18] Habib, E. and El Hadad, A. (2003) Occlusion de l'intestin grêle sur bride congénitale chez 16 adultes. Service de chirurgie viscérale et thoracique, hôpital Robert-Robert. Annales de Chirurgie, 128, 94-97. https://doi.org/10.1016/S0003-3944(02)00037-8

[19] Beyrout, I., Gargouri, F. and Gharbi, A. (2006) Late Post-Operative Adhesive Small-Bowel Occlusions. About 258 Cases. La Tunisie Médicale, 84, 9-15.

[20] Dia, A., Fall, B. and Thognon, Ph. (1991) Les occlusions intestinales par brides post-opératoires 79 observations. Journal de Chirurgie, 128, 548-551.

[21] Duron, J.J., Silva, N.J., Du Montcel, S.T. and Berger, A. (2006) Adhesive Postoperative Small Bowel Obstruction: Incidence and Risk Factors of Recurrence after Surgical Treatment: A Multicenter Prospective Study. Annals of Surgery, 244, 750-757. https://doi.org/10.1097/01.sla.0000225097.60142.68 